the ring-end of the lever and firmly rotates, flexes, abducts, adducts, or extends as the case may require, while the grpsum bandage is completed. The assistant must remember that the lever gives him great power and he must not too forcibly over-correct or the splint may be unbearable. One end of the retaining pin is left uncovered by the bandages so that it may be pulled out when the plaster has set. These pins, of course, are often lost, but a nurse can always supply a hairpin, one leg of which answers the

FIG. 8.

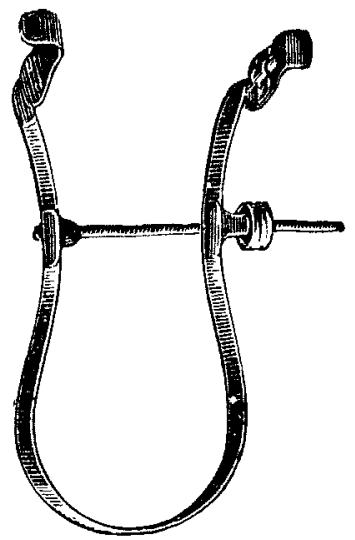

purpose perfectly. As soon as the gypsum has set the pin at the heel is withdrawn and the lever is then gently pulled out, leaving the plate embedded in gypsum. The plates can be used over and over again and as the first cost is very small a stock of various sizes for both feet can be kept in the hospital instrument store, or one can be made to order by any workman provided with such common materials as sheet brass, iron or steel wire, and copper rivets. I have used these sole plates regularly during the last two years at the

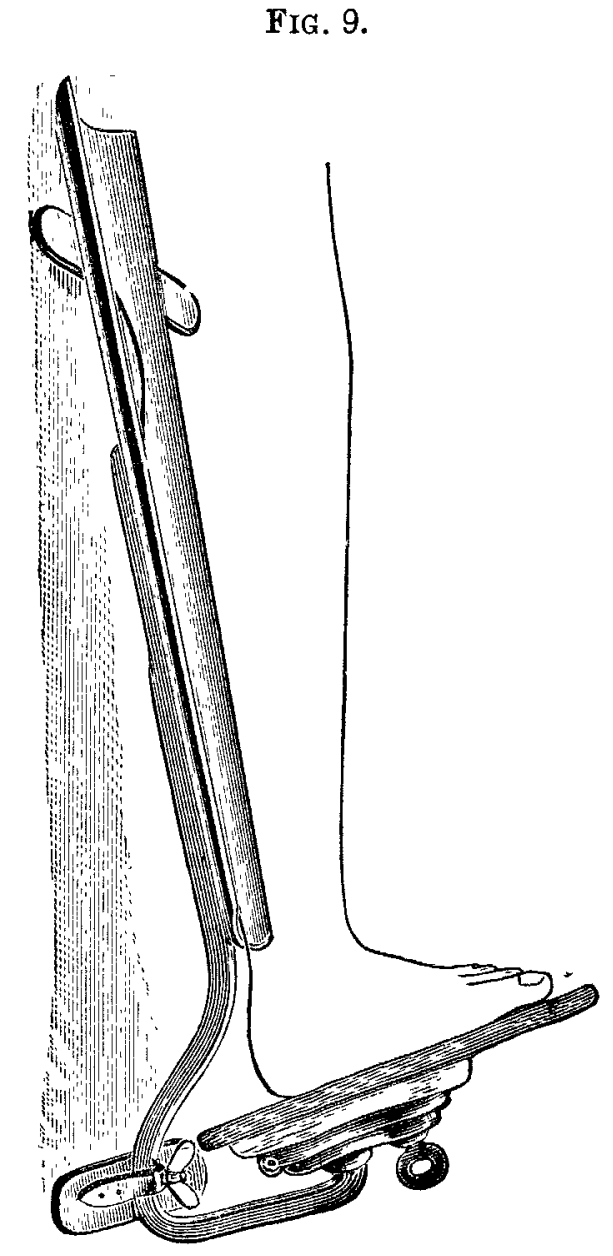

Royal National Orthopædic Hospital in London and have never known of any sore or other bad result following their use.

Figs. 5, 6, and 7 represent a bunion spring for the ambulant treatment of hallux valgus when for any reason the radical cure by operation is not practicable. I venture to claim for it these advantages: (1) it leaves the tender inner surface of the prominent joint free from pressure; (2) it allows free movements of extension and flexion; (3) it takes up little room in the boot; (4) it can be worn night and day ; and last and most important, it keeps up a gentle but steady correcting pressure. It consists of a thin and flat steel or phosphor-bronze spring which is twisted in a somewhat spiral form, extending from the outer side of the heel to the last phalanx of the great tne, where it is bent up to form a toe-post. Opposite and underneath the metatarso-phalangeal joint it has a flat hinge. The whole is covered with leather.

Fig. 8 shows an adjustable spring retractor or dummy assistant, intended to hold the toes apart during small operations, dressings, or examinations, and so save the services of an assistant. It resembles in design a pair of spring calipers or dividers. The bow is curved on the edge so as to rest on the dorsum of the foot. The shaped toe-plates are piroted so as to adjust themselves to the position of the toes against which they rest and the range of action of the spring is controlled by the nut, which spins easily on the cross pin.

Fig. 9 shows an universal foot splint for the treatment of deformities of that part after operations such as arthrodesis. The only point which calls for notice is the very strong ball-and-socket joint under the sole plate which allows it to be placed and kept in whatever position may be most desirable. This object is attained by using a large ball and clamping it with a ring after the manner of certain reading desks which are made for invalids. Fig. 10

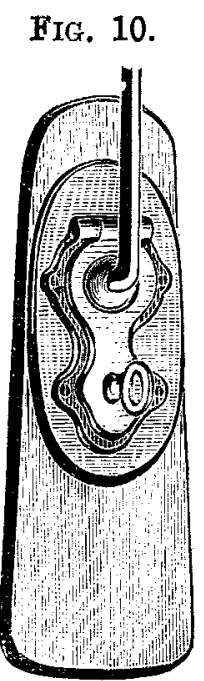

shows the under surface of the sole plate. This latter is made of wood, as is the leg plate, and to these the metal fittings are fastened with screws so that they can be easily removed and fixed to different sized plates. One set of fittings is thus available for a number of different cases, a point of some importance in a hospital.

All of the above-described appliances have been made for me by Mr. A. E. Evans, of 11, Osnaburgh-street, London, N.W., who has very efficiently carried out my instructions. Duchess-street, $\mathrm{W}$.

\section{A CASE OF CHRONIC INTUSSUSCEPTION WITH COMPLETE INVERSION OF THE VERMIFORM APPENDIX.}

\section{By J. W. STRUTHERS, M.B., Сн.B. EDIN., F.R.C.S. EDIN.,} ASSISTANT SURGEON TO THE LEITH HOSPITAL.

A FEW cases of intusussception associated with complete or partial inversion of the vermiform appendix have been recorded, but the combination is so rare that it appears worth while to add a report of the following case to the existing records.

The patient, a poorly-developed girl, five years old, began to suffer from severe attacks of abdominal pain and diarrhoea two months before her admission to Leith Hospital on August 10th, 1906. The attacks of pain came on about once in 24 hours, often at night, and were so severe as to make the child scream out and roll about in agony. No special note was taken by the mother of the character of the motions and no blood was noticed in them at the beginning of the illness. There was no romiting until two 
days before admission to hospital. The patient was taken to the medical out-patient department of the hospital soon after her illness began and was treated for summer diarrhœen, nothing abnormal being detected in the abdomen. The treatment relieved but did not cure the condition, for the diarrhœa continued, and five weeks after the illness began streaks of blood were noticed in the motions. A week later the mother found that something was protruding from the anus after the passage of a motion. She returned the protrasion without difficulty but it came down frequently after its first appearance. Two days before the child's admission to hospital, in the eighth week of her illness, she suddenly became worse. She began to vomit and vomited repeatedly until admission. The abdominal pain became much more severe and the child's strength failed rapidly. The protrusion at the anus appeared to increase in size and though it could still be returned it came down again soon after reduction and was almost continuously outside the anus for two days before admission. The child was again taken to the hospital and was at once admitted.

On examination the patient was found to be a pale, emaciated, sickly-looking child, apparently much reduced in strength. Her temperature was normal, the respirations were 24 , and the pulse-rate was 108 per minute. The abdomen was prominent but not markedly distended. The muscular wall was not rigid and palpation revealed a firm, elongated mass, easily felt, occupying the left lumbar and iliac regions and passing down into the pelvis. Protruding from the anus was a purplish-coloured mass, obviously of intestine coiled on itself. At its apparent apex was a dimple and close to this was a polypoid projection about one and a half inches long. The nature of this, which ultimately proved to be the appendix turned inside out, was not at first recognised.

Without further delay the child was taken to the operating theatre and anæsthetised, the C.E. mixture dropped on an open mask being used. The bladder was emptied by catheter and the prolapsed intestine was returned by an assistant. The abdomen was then opened through the left rectus muscle near the middle line. The descending colon at once presented moderately distended by the intussusceptum but not apparently otherwise affected. Two fingers of one hand were passed into the pelvis and reached below the apex of the intussusceptum in the rectum without difficulty. By moderate pressure the intussusceptum was gradually made to travel back along the descending, transverse, and ascenaing colon, which were successively brought out at the wound, an unusually long ascending and descending mesocolon making, this easy. No adhesions had formed between the opposing peritoneal surfaces, and the wall of the intestine was only slightly thickened in the region of the cæoum and ascending colon. Reduction was consequently casy and when the ileo-creal junction and the crecum finally appeared it was thought that reduction was complete. On inspecting the cæcum, however, it was found that there was apparently no appendix and the site where it should have arisen was marked by a dimple in the cæcal wall. Palpation then revealed the fact that the appendix was projecting into the cæcum. After one or two ineffectual attempts to express it the cæcum was packed round with gauze, opened by a longitudinal incision on its antero external aspect, and the appendix at once found projecting into its interior and completely inverted. It was amputated at the base, the edges of the mucous membrane at its origin were united by a silk stitch, and the incision in the crcum was closed by a double row of stitches in the usual way. The abdominal wound was then closed, no drainage being employed. The child's condition at the end of the operation appeared little worse than at the beginning. There was no vomiting after the operation and the child made an excellent recovery. She was dizcharged from hospital in good health five weeks after admission.

The appendix was hardened and then examined by making a longitudinal and cross sections through it. It was one and a half inches long and half an inch across at the base. The distal two-thirds of the mucous membrane were replaced by a layer of whitish adherent lymph; the proximal one-third showed some punctate hæmorrhages and general congestion. On section it was found that the peritoneal tube which must bave been present when inversion took place was obliterated, except for a few millimetres at the base of the appendix. The process of inversion had evidently been followed by exudation and organisation and the condition had existed long enough to allow of organisation being well advanced. Microscopical examination of the appendix near its tip and base revealed nothing of special note except that the main vessels were not thrombosed. The mucous membrane towards the tip had apparently necrosed and been rep!aced by the layer of lymph noted above. Otherwise the appendix was in a good state of preservation and showed o.ly general congestion with a few small hamorrhages. The line of the peritoneal coat could not be detected and the central part of each section was occupied by young connective tissue round the main vessels of the appendix.

As the child was not under observation from the beginning of the illness it is impossible to say exactly how long the intussusception had existed. Its apex appeared outside the anus a fortnight before the operation, so it must have been present for two weeks, while it may have been the sole cause of the illness and been present for eight weeks. In all pro. bability the process began with the inversion of the appendix, for it is difficult to believe that the appendix could have been turned outside in after being drawn in between the ileum and the cæcum in an ordinary ileo-cæcal invagination. The inverted appendix probably acted as a foreign body and set up violent peristalsis in the cæcum and so led to the invagination of the ileo-crcal valve. What conditions, anatomical or pathological, would lead to an inversion of the appendix it is difficult to imagine, and one must in the meantime be content. merely to record the fact of such an occurrence. In common with other recorded cases of chronic intussusception, an unusually long mesocolon was present in this case, so that the entire colon could be brought out without difficulty through a wound to the left of the middle-line. Owing to the presence of this long mesocolon the intussusceptum was able to pass along the large intestine and project at the anus without strangulation occurring and fortunately without sufficient congestion and irritation being set up to cause the formation of adhesions, except between the opposing peritoneal surfaces of the appendix. It might be suggested that in these circumstances a trial of reduction by inflation or injection would have been successful in relieving the condition. Had injection successfully reduced the ileo-cæcal invagination, however, the inverted appendix must have remained in stat? $q u o$ and would have almost certainly led to a recurrence.

In an almost similar case recorded by Pitts the intussusceptum prolapsed from the anus a fortnight before operation, and reduction, apparently successful, was carried out by manipulation. The child remained well for some days and was discharged from hospital, only to be readmitted a few days later with a recurrence of the condition, except that the intussusceptum did not again prolapse from the anus. At the operation the appendix was found completely inverted into the cæcum and was removed after opening the cæcum, exactly as in the case under consideration. The child recovered. In two of the other four cases which I have found recorded, one by McKidd in 1858, the other by McGraw in 1897, the inversion of the appendix appears to have been complete. In the remaining cases, reported by Wright and Waterhouse, the inversion was partial and affected the proximal part of the appendix only. In four out of six cases, therefore, the inversion was complete, and in two it was incomplete; three of the patients with complete inversion were operated on and all recovered; the fourth case, reported by McKidd in 1858, was of course not operated on. Of the cases with partial inversion one recovered and one died.

Bibliography.-McKidd: Edinburgh Medical Journal. 1858. McGraw: Brit. Med. Jour, 1897. Pitts: THE LANCET, June 12th, 1897, p. 1602. Wright: Brit. Med. Jour., 1897. Waterhouse: Transactions of the Pathological Society of London, 1898. Edinburgh.

\section{ON THE INCREASED MORTALITY IN ENGLAND AND WALES FROM KIDNEY DISEASES, WITH SPECIAL REFER- ENCE TO BORON PRESERVA- TIVES AS A FACTOR THEREIN.}

By B. FARADAY GILes, M.D. DurH.

As chairman of the commission now sitting in America on the Pure Food Bills Dr. Wiley is stated to have said: "There is a low death rate in England, but the low rate is in pulmonary diseases, $\&$ c., while there has been an increase of 30 per cent. in kidney diseases, \&c., ...... due no doubt to the use of colouring matter and preservatives." Again, Dr. Richard Jones in his presidential address on Food and Food Preservatives, says: "I have always stated that it has been proved that 